\title{
High-sensitivity C-reactive protein and impaired coronary vasoreactivity in young men with uncomplicated type 1 diabetes
}

\author{
J. Sundell ${ }^{1,2}$ - T. Rönnemaa ${ }^{2}$ H. Laine ${ }^{1,2}$ - O. T. Raitakari ${ }^{1,3} \cdot$ M. Luotolahti ${ }^{3} \cdot$ P. Nuutila ${ }^{1,2} \cdot$ J. Knuuti $^{1}$ \\ 1 Turku PET Centre, Turku University Central Hospital, Turku, Finland \\ 2 Department of Medicine, University of Turku, Finland \\ ${ }^{3}$ Department of Clinical Physiology, University of Turku, Finland
}

\section{Abstract}

Aims/hypothesis. Elevated high-sensitivity C-reactive protein (hsCRP) concentrations indicate increased risk of future coronary events. The association between hsCRP and coronary vasoreactivity has not yet been examined in type 1 diabetic subjects.

Methods. We studied 18 young men who were non-smokers and who had uncomplicated type 1 diabetes. The diabetic subjects were divided into two groups, according to their median hsCRP concentration, as follows: (i) subjects with slightly elevated hsCRP (median $0.76 \mathrm{mg} / \mathrm{l}$, range 0.47-4.73 mg/l, $n=8$ ); and (ii) subjects with low hsCRP (median $0.32 \mathrm{mg} / \mathrm{l}$, range $0.11-0.35 \mathrm{mg} / \mathrm{l}, n=10)$. In addition we investigated 22 non-diabetic age-matched subjects (hsCRP: median $0.42 \mathrm{mg} / \mathrm{l}$, range $0.11-$ $1.31 \mathrm{mg} / \mathrm{l})$. Resting myocardial blood flow and hyperaemic adenosine-stimulated flow during euglycaemic-hyperinsulinaemic clamp were determined using positron emission tomography and oxygen-15 labelled water.
Results. Diabetic subjects with slightly elevated hsCRP had significantly higher hsCRP concentrations than nondiabetic subjects $(p=0.008)$. Resting myocardial blood flow was similar (NS) in diabetic subjects with slightly elevated hsCRP $\left(0.79 \pm 0.19 \mathrm{ml} \cdot \mathrm{g}^{-1} \cdot \mathrm{min}^{-1}\right)$ or low hsCRP $\left(0.81 \pm 0.15 \mathrm{ml} \cdot \mathrm{g}^{-1} \cdot \mathrm{min}^{-1}\right)$ and non-diabetic subjects $\left(0.80 \pm 0.19 \mathrm{ml} \cdot \mathrm{g}^{-1} \cdot \mathrm{min}^{-1}\right)$. Adenosine infusion induced a significant increase in blood flow in all study subjects $(p<0.001)$ but was blunted in diabetic subjects with slightly elevated hsCRP $\left(3.42 \pm 0.61 \mathrm{ml} \cdot \mathrm{g}^{-1} \cdot \mathrm{min}^{-1}\right)$ when compared with diabetic subjects with low hsCRP $\left(5.08 \pm 1.65 \mathrm{ml} \cdot \mathrm{g}^{-1} \cdot \mathrm{min}^{-1}, p=0.02\right)$ or non-diabetic subjects $\left(4.51 \pm 1.36 \mathrm{ml} \cdot \mathrm{g}^{-1} \cdot \mathrm{min}^{-1}, p=0.04\right)$. Adenosine-stimulated flow was inversely correlated with hsCRP concentrations in all diabetic subjects $(r=-0.70, p=0.001)$.

Conclusions/interpretation. In young subjects with uncomplicated type 1 diabetes, even slightly elevated hsCRP concentrations are associated with reduced coronary vasoreactivity.

Keywords Adenosine $\cdot$ hsCRP $\cdot$ Myocardial blood flow $\cdot$ Positron emission tomography $\cdot$ Type 1 diabetes
Received: 14 May 2004 / Accepted: 13 July 2004

Published online: 24 November 2004

(C) Springer-Verlag 2004

\section{J. Sundell (}

Turku PET Centre, Turku University Central Hospital,

P.O. Box 52, 20521 Turku, Finland

E-mail: jan.sundell@utu.fi

Tel.: +358-2-3130000, Fax: +358-2-2318191

Abbreviations: $\left[{ }^{15} \mathrm{O}\right] \mathrm{CO}$, oxygen-15-labelled carbon monoxide $\left[{ }^{15} \mathrm{O}\right] \mathrm{H}_{2} \mathrm{O}$, oxygen-15-labelled water $\cdot$ hsCRP, high-sensitivity C-reactive protein PET, positron emission tomography ·

ROI, region of interest

\section{Introduction}

In the general population, even slightly elevated highsensitivity C-reactive protein (hsCRP) concentrations $(>0.57 \mathrm{mg} / \mathrm{l})$ have been found to indicate increased risk of future coronary events [1]. Endothelial dysfunction appears to be one of the earliest abnormalities in the development of coronary artery disease [2]. Poor glycaemic control and long-term diabetic complications are associated with endothelial dysfunction, which promotes adherence of leucocytes to the vessel walls and induces inflammatory response $[3,4]$. In ad- 
Table 1. Characteristics of the study subjects

\begin{tabular}{|c|c|c|c|c|}
\hline & \multicolumn{3}{|c|}{ Diabetic subjects } & \multirow[t]{2}{*}{ Non-diabetic subjects } \\
\hline & All & Elevated hsCRP & Low hsCRP & \\
\hline hsCRP, median (mg/l) & 0.35 & $0.76^{*}$ & 0.32 & 0.42 \\
\hline hsCRP, range $(\mathrm{mg} / \mathrm{l})$ & $0.11-4.73$ & $0.47-4.73$ & $0.11-0.35$ & $0.11-1.31$ \\
\hline Age, years & $34(8)$ & $35(8)$ & $34(8)$ & $34(5)$ \\
\hline Dose of insulin, $\mathrm{U} / \mathrm{kg}$ & $0.56(0.17)$ & $0.57(0.17)$ & $0.56(0.18)$ & - \\
\hline $\mathrm{BMI}, \mathrm{kg} / \mathrm{m}^{2}$ & $24.7(2.3)$ & $25.0(2.8)$ & $24.4(1.9)$ & $25.5(2.0)$ \\
\hline Blood pressure, $\mathrm{mmHg}$ & $120 / 68(9 / 9)$ & $118 / 70(8 / 9)$ & $122 / 66(9 / 9)$ & $122 / 71(11 / 10)$ \\
\hline Cholesterol, mmol/l & $4.6(0.8)$ & $4.8(1.0)$ & $4.4(0.7)$ & $4.9(0.7)$ \\
\hline HDL cholesterol, mmol/l & $1.4(0.3)$ & $1.5(0.4)$ & $1.4(0.2)$ & $1.4(0.4)$ \\
\hline Triglycerides, mmol/1 & $0.9(0.5)$ & $0.9(0.3)$ & $0.9(0.6)$ & $0.9(0.3)$ \\
\hline
\end{tabular}

Values are means (SD) unless otherwise stated. $* p<0.05$ vs diabetic subjects with low hsCRP and non-diabetic subjects; ${ }^{\dagger} p<0.05$ vs diabetic subjects

dition, to reflect the continuous inflammatory process, CRP may be directly related to the development of atherosclerosis [5]. Diabetic patients usually have increased hsCRP concentrations [6]. Thus, inflammatory response appears to be important in the development of coronary artery disease in subjects with type 1 diabetes.

Coronary vasoreactivity has been found to be decreased in diabetic patients $[7,8,9,10,11]$. However, most of these previous studies included patients with both type 1 and type 2 diabetes and/or included diabetic patients with other potentially confounding factors such as diabetic complications, smoking, hypertension, obesity and lipid abnormalities, which are known to impair coronary vasoreactivity. The question of whether coronary vasoreactivity is impaired in subjects with uncomplicated type 1 diabetes who are otherwise healthy is still controversial [10, 12, 13, 14]. Elevated hsCRP concentrations are associated with markers of endothelial dysfunction [15]. However, no previous work addressing the effect of hsCRP on myocardial perfusion has been undertaken in patients with type 1 diabetes.

In the present study we investigated whether elevated hsCRP is associated with impaired coronary vasoreactivity in young subjects with uncomplicated type 1 diabetes. Resting myocardial blood flow and adenosine-stimulated flow during euglycaemic- hyperinsulinaemic clamp were measured in diabetic and non-diabetic subjects using positron emission tomography (PET) and oxygen- ${ }^{15}$-labelled water $\left(\left[{ }^{15} \mathrm{O}\right] \mathrm{H}_{2} \mathrm{O}\right)$.

\section{Subjects and methods}

Subjects. Characteristics of the study subjects are shown in Table 1 . Eighteen subjects with uncomplicated type 1 diabetes, and 22 non-diabetic age-matched subjects volunteered for the study. The diabetic subjects were divided into two groups, according to their median hsCRP concentration, as follows: (i) subjects with slightly elevated hsCRP (median $0.76 \mathrm{mg} / \mathrm{l}$, range $0.47-4.73 \mathrm{mg} / \mathrm{l}, n=8$ ); and (ii) subjects with low hsCRP (median $0.32 \mathrm{mg} / \mathrm{l}$, range $0.11-0.35 \mathrm{mg} / \mathrm{l}, n=10$ ). The subjects were recruited from diabetes outpatient clinics in Turku, Finland. All study participants were non-smokers, were otherwise healthy, and were taking no medication other than insulin (diabetic subjects). The subjects had no clinical signs or symptoms of heart disease, nephropathy (including microalbuminuria), retinopathy or neuropathy. Each subject gave written informed consent, and the studies were conducted according to the guidelines of the Declaration of Helsinki. The study protocols were also approved by the Ethics Committee of the Turku University Central Hospital.

Study design. PET studies were performed after an overnight fast. The subjects were instructed to avoid all caffeine-containing food and drink for $12 \mathrm{~h}$ before the start. On the morning of the PET study, to avoid hypoglycaemia, the normal dose of intermediate-acting insulin was reduced by one-third and shortacting insulin was withdrawn in diabetic subjects. In the first instance, myocardial blood flow was measured at rest. Thereafter, euglycaemic-hyperinsulinaemic clamp was started for $60 \mathrm{~min}$ and then myocardial blood flow was measured during hyperaemia induced by adenosine $\left(140 \mu \mathrm{g} \cdot \mathrm{kg}^{-1} \cdot \mathrm{min}^{-1}\right.$ for 5 min i.v.; Fig. 1). The insulin infusion was continued until the second perfusion measurement was performed. Electrocardiogram and heart rate were monitored continuously during the studies. Blood pressure was monitored using an automatic oscillometric blood pressure monitor (OMRON 711; Omron Matsuaka, Japan).

Euglycaemic-hyperinsulinaemic clamp technique and wholebody glucose uptake. Insulin and glucose were infused via a catheter inserted into the right antecubital vein. Arterialised venous blood samples were withdrawn from a heated left antecubital vein. Insulin (Actrapid Human; Novo Nordisk, Copenhagen, Denmark) was administered in a primed continuous manner at a rate of $1 \mathrm{mU} \cdot \mathrm{kg}^{-1} \cdot \mathrm{min}^{-1}$, starting $60 \mathrm{~min}$ before the adenosine-stimulated myocardial blood flow measurement and continuing until the perfusion measurement was performed. Normoglycaemia was maintained by infusing $20 \%$ glucose at 


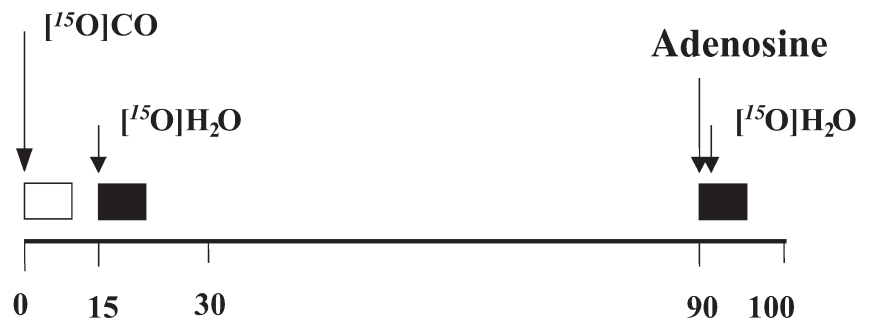

Time (min) \begin{tabular}{c|} 
Insulin infusion \\
$\left(\mathbf{1} \mathrm{mU} \cdot \mathbf{k g}^{-1} \cdot \mathrm{min}^{-1}\right)$
\end{tabular}

\section{$20 \%$ glucose infusion}

Fig. 1. Design of the study. Myocardial perfusion was measured with $\left[{ }^{15} \mathrm{O}\right] \mathrm{H}_{2} \mathrm{O}$ under basal conditions and during simultaneous adenosine infusion and euglycaemic-hyperinsulinaemic clamp. Insulin was infused at a rate of $1 \mathrm{mU} \cdot \mathrm{kg}^{-1} \cdot \mathrm{min}^{-1}$. Black boxes, perfusion measurements

the rate determined by plasma glucose concentrations, which were measured every $5 \mathrm{~min}$. Serum insulin and non-esterified fatty acids were measured every $30 \mathrm{~min}$ during clamp. Wholebody glucose uptake, a measurement of insulin sensitivity, was calculated from the glucose infusion rate after correcting for changes in the glucose pool size [16].

Production of [15O]CO and [15O]H2O. For production of ${ }^{15} \mathrm{O}$, a low-energy deuteron accelerator Cyclone 3 was used (Ion Beam Application, Louvain-la-Neuve, Belgium). Oxygen${ }^{15}$-labelled carbon monoxide $\left(\left[{ }^{15} \mathrm{O}\right] \mathrm{CO}\right)$ was produced in a conventional way [17], and $\left[{ }^{15} \mathrm{O}\right] \mathrm{H}_{2} \mathrm{O}$ was produced using dialysis techniques in a continuously working water module [18]. Sterility and pyrogenity tests for water, and chromatographic analysis for gases were performed to verify the purity of the products.

Image acquisition, processing and correction. The subjects were positioned supine in a 15-slice ECAT 931/08-12 tomograph (Siemens/CTI, Knoxville, Tenn., USA). After the transmission scan, the subjects' nostrils were closed and they inhaled $\left[{ }^{15} \mathrm{O}\right] \mathrm{CO}(\sim 2.5 \mathrm{GBq})$ for $2 \mathrm{~min}$ through a three-way inhalation flap-valve $(0.14 \% \mathrm{CO}$ mixed with room air). After the inhalation, 2 min were allowed for the $\mathrm{CO}$ to combine with haemoglobin in red blood cells before a static scan (4 min) was started. During the scan, three blood samples were drawn at 2 min intervals and blood radioactivity was measured immediately using a well counter (Bicron 3MW3/3; USA). A 10-min period was allowed for $\left[{ }^{15} \mathrm{O}\right] \mathrm{CO}$ radioactive decay before the flow measurements. Flow was measured at rest and $60 \mathrm{~s}$ after intravenous administration of adenosine. Then, $\left[{ }^{15} \mathrm{O}\right] \mathrm{H}_{2} \mathrm{O}$ $(\sim 1.5 \mathrm{GBq})$ was injected intravenously and dynamic scanning was started for 6 min $(6 \times 5 \mathrm{~s}, 6 \times 15 \mathrm{~s}, 8 \times 30 \mathrm{~s})$. All data were corrected for dead-time, decay and photon attenuation and were reconstructed into a $128 \times 128$ matrix. The final in-plane resolution in reconstructed and Hann-filtered ( 0.3 cycles/s) images was $9.5 \mathrm{~mm}$ (full-width half-maximum).

Calculation of regional myocardial blood flow. Regions of interest (ROIs) were drawn in the lateral and anterior wall of the left ventricle in four representative transaxial slices as previously described [19]. The ROIs were outlined in the baseline images and copied to the images obtained after adenosine administration. Values of regional myocardial blood flow (ex- pressed in $\mathrm{ml} \cdot \mathrm{g}^{-1}$ of tissue $\mathrm{min}^{-1}$ ) were calculated according to the previously published methodology using the single compartment model [20]. The arterial input function was obtained from the left ventricular time-activity curve using a previously validated method [21] in which corrections were made for the limited recovery of the left ventricular ROI and the spillover from the myocardial signals. The average blood flow of the lateral and anterior part of the myocardium showed the lowest coefficient of variation and was used in further analysis. The variation coefficient of myocardial blood flow measurements using PET and $\left[{ }^{15} \mathrm{O}\right] \mathrm{H}_{2} \mathrm{O}$ is $14 \pm 11 \%$ at rest and $16 \pm 9 \%$ during hyperaemic flow.

Retinal photography. Retinal photography was performed after mydriatic instillation using a Canon CR4-45NM fundus camera (Canong, Kanagawa, Japan), and one $45^{\circ}$ field photograph, including areas of papilla and macula, was taken from each eye. Polaroid photo prints were analysed by an experienced diabetologist.

Echocardiographic examination. To rule out silent ischaemia the subjects underwent echocardiographic examination during rest and during bicycle exercise. All echocardiographic recordings and analyses were performed by the same experienced investigator using a commercially available ultrasound scanner (Acuson 128XP/10; Acuson, Mountain View, Calif., USA). Standard echocardiographic views of the left ventricle were obtained and cardiac dimensions were measured, in the first instance at rest. Thereafter, an upright bicycle-ergometer exercise test was performed by increasing workload by $20 \mathrm{~W}$ at 1 min intervals. The test was continued until extreme fatigue when at least $90 \%$ of the predicted maximum heart rate was reached. The echocardiograms were recorded before and immediately after the exercise.

Analytical methods. Venous blood samples were taken after $12 \mathrm{~h}$ of overnight fast. Serum hsCRP was measured using a latex immunoturbidimetric method (Wako Chemicals, Neuss, Germany; detection limit $0.06 \mathrm{mg} / \mathrm{l})$. $\mathrm{HbA}_{1} \mathrm{c}$ was measured by high-pressure liquid chromatography. Plasma glucose was determined by the glucose oxidase method. Serum insulin concentrations were measured using a time-resolved immunofluorometric assay (Autodelfia; Wallac, Turku, Finland). Serum total cholesterol, HDL cholesterol and triglyceride concentrations were measured by standard enzymatic methods (Boehringer Mannheim, Germany) using a fully automated analyser (Hitachi 704; Hitachi, Tokyo, Japan). The LDL cholesterol concentration was calculated using the Friedewald formula. The first morning urine sample was analysed to define the ratio of urinary albumin $(\mathrm{mg} / \mathrm{l})$ to urinary creatine $(\mathrm{mmol} / \mathrm{l})$ in order to screen for microalbuminuria [22]. If the screening test gave a positive result ( $\geq 2 \mathrm{mg} / \mathrm{mmol}$ ), urinary albumin excretion rate $(\mu \mathrm{g} / \mathrm{min})$ was measured during the night. Urinary albumin was determined by immunonephelometry (Behring) using antiserum from Dakopatts (Glostrup, Denmark). Microalbuminuria was defined as an albumin excretion rate of $20 \mu \mathrm{g} / \mathrm{min}$ or higher in at least two of the three overnight urine samples.

Statistical methods. The results are expressed as median (range) for hsCRP and as mean \pm SD for other study variables. Student's paired and unpaired $t$ tests as well as Wilcoxon paired and unpaired tests were used when appropriate. For correlation analysis, Spearman's correlation coefficients were calculated. Multivariate modelling was performed using linear regression analysis. The distribution of hsCRP was highly skewed, and even after log-transformation, the test for normality (Shapiro-Wilk) suggested non-normal distribution. There- 
fore, in the multivariate models, hsCRP was treated as a dichotomised variable using median value as the cut-off point. We considered $p$ values of less than 0.05 to be statistically significant. All statistical tests were performed using the SAS statistical analysis system (SAS Institute, Cary, N.C., USA).

\section{Results}

Characteristics of the study participants. No differences were detected between the study subjects in terms of the traditional risk factors, except that $\mathrm{HbA}_{1} \mathrm{c}$ was lower in non-diabetic subjects than in diabetic subjects (Table 1). None of the diabetic subjects had microalbuminuria, retinopathy or any signs or symptoms of neuropathy. Mass, dimensions and function of the left ventricle as determined by echocardiography and stress echocardiography were within the normal range in all study participants [23]. All subjects had a normal exercise capacity, were asymptomatic, had no diagnostic ST-changes in electrocardiograms and had no wall motion disturbances either at rest or immediately after the maximal exercise.

Metabolic and hormonal characteristics. Plasma glucose, serum insulin and non-esterified fatty acid concentrations as well as insulin-stimulated whole-body glucose uptake values were similar in the two diabetic groups during the PET studies (Table 2). Plasma glucose and serum insulin concentrations were lower in non-diabetic subjects than in diabetic subjects $(p<0.05)$. During clamp, plasma glucose concentrations decreased significantly in diabetic subjects $(p<0.05)$. Serum insulin concentrations increased and serum non-esterified fatty acid concentrations decreased significantly in all study subjects during clamp $(p<0.01)$. Whole-body glucose uptake tended to be reduced in diabetic subjects compared with in nondiabetic subjects $(p<0.1$; Table 2$)$.

Haemodynamic measurements during PET studies. During clamp, adenosine infusion induced a significant and similar increase in heart rate and rate-pressure product in all studied groups $(p<0.001$; Table 3$)$. No differences were detected between the study groups in terms of heart rate, blood pressure or rate-pressure product values (Table 3).

Myocardial blood flow. When all studied diabetic subjects $(n=18)$ were compared with non-diabetic subjects, myocardial blood flow values were similar at baseline $\left(0.80 \pm 0.17\right.$ vs $0.80 \pm 0.19 \mathrm{ml} \cdot \mathrm{g}^{-1} \cdot \mathrm{min}^{-1}$, $p=0.94$ ) and during simultaneous clamp and adenosine infusion $\left(4.34 \pm 1.52\right.$ vs $4.51 \pm 1.36 \mathrm{ml} \cdot \mathrm{g}^{-1} \cdot \mathrm{min}^{-1}$, $p=0.72$ ). When diabetic subjects were divided into two groups based on hsCRP concentrations, basal myocardial blood flow was not different in the two groups $\left(0.79 \pm 0.19\right.$ vs $0.81 \pm 0.15 \mathrm{ml} \cdot \mathrm{g}^{-1} \cdot \mathrm{min}^{-1}$ [subjects with slightly elevated hsCRP vs subjects with
Table 2. Metabolic and hormonal characteristics of the study subjects

\begin{tabular}{lcc}
\hline & Fasting & During clamp \\
\hline Plasma glucose, mmol/l & & \\
All (D) & $7.8(3.4)$ & $6.5(2.1)^{* *}$ \\
Elevated hsCRP (D) & $7.5(3.4)$ & $6.7(2.1)^{* *}$ \\
Low hsCRP (D) & $8.1(3.5)$ & $6.4(2.1)^{* *}$ \\
Non-diabetic subjects & $5.4(0.4)^{\dagger}$ & $5.1(0.5)^{\dagger}$ \\
Serum insulin, mU/1 & & \\
All (D) & & \\
Elevated hsCRP (D) & $17.8(7.9)$ & $77.7(20.2)^{* *}$ \\
Low hsCRP (D) & $18.8(10.6)$ & $73.4(9.3)^{* *}$ \\
Non-diabetic subjects & $17.2(5.7)$ & $80.5(25.0)^{* *}$ \\
Serum NEFA, $\mu$ mol/1 & $12.0(6.8)^{\dagger}$ & $60.9(17.6)^{* *}$, \\
All (D) & & \\
Elevated hsCRP (D) & $470(250)$ & $90(70)^{* * *}$ \\
Low hsCRP (D) & $460(260)$ & $60(50)^{* *}$ \\
Non-diabetic subjects & $470(260)$ & $110(80)^{* *}$ \\
WBGU, $\mu$ mol·kg-1·min-1 & $490(230)$ & $60(40)^{* *}$ \\
All (D) & & \\
Elevated hsCRP (D) & & $27.2(11.1)$ \\
Low hsCRP (D) & & $29.2(10.9)$ \\
Non-diabetic subjects & & $25.9(11.5)$ \\
\hline
\end{tabular}

Values are means (SD). D, subjects with type 1 diabetes; WBGU, whole-body glucose uptake. ${ }^{* *} p<0.01$ vs fasting; ${ }^{\dagger} p<0.05$ vs diabetic subjects

Table 3. Haemodynamic data during the PET study

\begin{tabular}{lcl}
\hline & Basal & Adenosine and clamp \\
\hline Heart rate, bpm & & \\
All (D) & $61(15)$ & $105(17)^{* * *}$ \\
Elevated hsCRP (D) & $62(12)$ & $100(18)^{* * *}$ \\
Low hsCRP (D) & $61(17)$ & $109(15)^{* * *}$ \\
Non-diabetic subjects & $58(9)$ & $103(10)^{* * *}$ \\
& & \\
Systolic BP, mmHg & & \\
All (D) & $120(9)$ & $126(10)$ \\
Elevated hsCRP (D) & $118(8)$ & $121(11)$ \\
Low hsCRP (D) & $123(9)$ & $129(8)$ \\
Non-diabetic subjects & $122(11)$ & $129(16)$ \\
& & \\
Diastolic BP, mmHg & & \\
All (D) & $68(9)$ & $71(8)$ \\
Elevated hsCRP (D) & $70(9)$ & $69(9)$ \\
Low hsCRP (D) & $66(9)$ & $73(6)$ \\
Non-diabetic subjects & $71(10)$ & $73(12)$ \\
RPP, mmHg/min & & \\
All (D) & & \\
Elevated hsCRP (D) & $7267(1644)$ & $12755(1751)^{* * *}$ \\
Low hsCRP (D) & $7620(2756)$ & $14414(2167)^{* * *}$ \\
Non-diabetic subjects & $7031(1160)$ & $13160(1909)^{* * *}$ \\
\hline
\end{tabular}

Values are means (SD). D, subjects with type 1 diabetes; RPP, rate-pressure product (systolic $\mathrm{BP} \mathrm{x}$ heart rate). $* * * p<0.001$ vs basal 


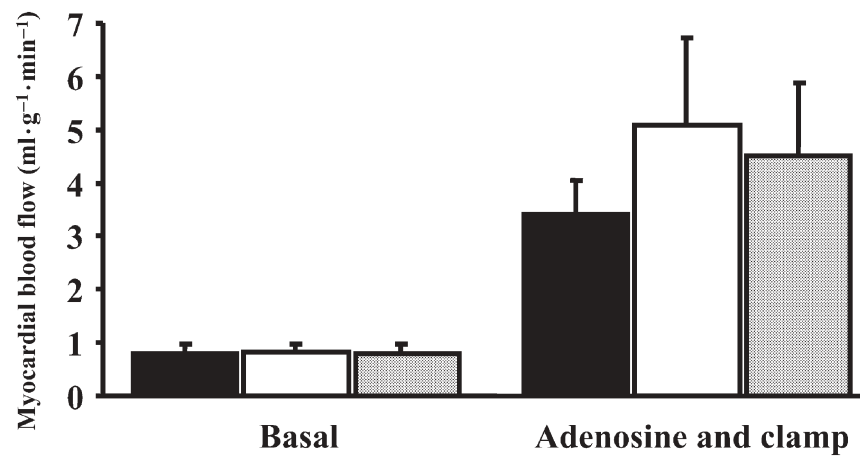

Fig. 2. Myocardial blood flow (mean, SD) under basal conditions and during simultaneous adenosine and clamp in type 1 diabetic subjects with slightly elevated (black bars) or low (white bars) hsCRP, and in healthy non-diabetic subjects (grey bars). Adenosine-stimulated flow was significantly reduced in diabetic subjects with slightly elevated hsCRP compared with in diabetic subjects with low hsCRP or in non-diabetic subjects $(p<0.05)$

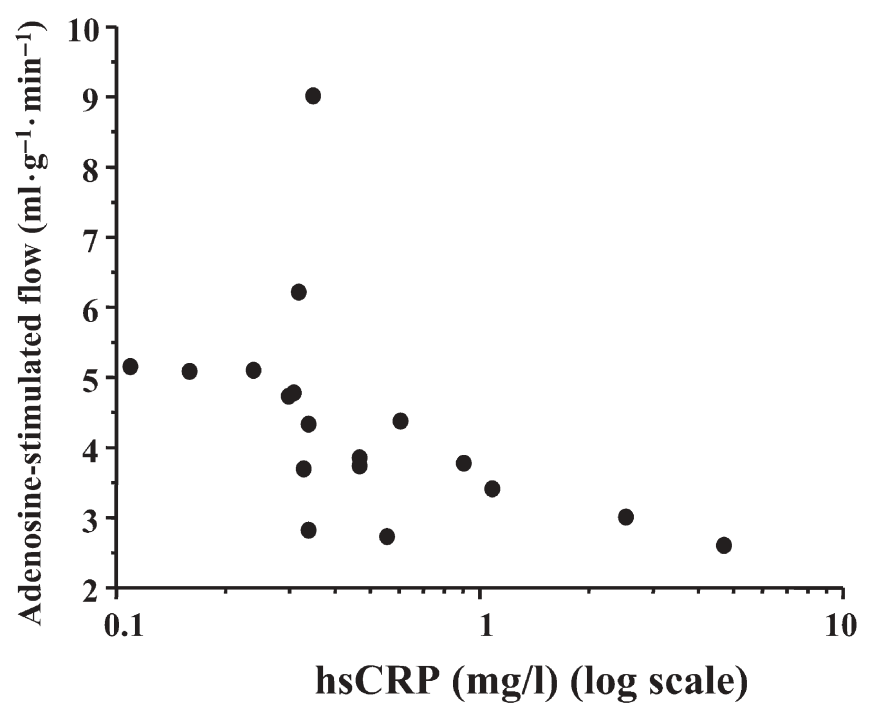

Fig. 3. Association between coronary vasoreactivity and hsCRP in diabetic subjects. Adenosine-stimulated flow during clamp was inversely correlated with hsCRP concentrations in all diabetic subjects $(r=-0.70, p=0.001)$

low hsCRP], $p=0.86$; Fig. 2). During clamp, adenosine infusion induced a significant increase in blood flow in all study subjects $(p<0.001)$, but the flow was significantly lower in diabetic subjects with slightly elevated $\mathrm{hsCRP}\left(3.42 \pm 0.61 \mathrm{ml} \cdot \mathrm{g}^{-1} \cdot \mathrm{min}^{-1}\right)$ than in diabetic subjects with low hsCRP $\left(5.08 \pm 1.65 \mathrm{ml} \cdot \mathrm{g}^{-1} \cdot \mathrm{min}^{-1}\right.$, $p=0.02)$ or non-diabetic subjects $\left(4.51 \pm 1.36 \mathrm{ml} \cdot \mathrm{g}^{-}\right.$ 1. $\mathrm{min}^{-1}, p=0.04$; Fig. 2). No difference was detected in terms of adenosine-stimulated flow during clamp between diabetic subjects with low hsCRP and non-diabetic subjects ( $p=0.31$; Fig. 2 ). Adenosine-stimulated flow during clamp was inversely correlated with hsCRP concentration in all diabetic subjects $(r=-0.70$, $p=0.001$; Fig. 3), whereas no significant correlation was detected in non-diabetic subjects $(r=-0.26$, $p=0.23$ ).
In a stepwise multivariate model adjusted for age, BMI, serum lipids and blood pressure, the hsCRP group remained independently associated with adenosine-stimulated flow in the diabetic subjects $(\beta=-$ $1.30 \pm 0.47, p=0.016)$.

\section{Discussion}

In the present study we demonstrate the novel finding that even slightly elevated hsCRP concentrations are associated with impaired coronary vasoreactivity in young subjects with uncomplicated type 1 diabetes. In contrast, diabetic subjects with low hsCRP concentrations have normal coronary vasoreactivity.

In previous studies coronary vasoreactivity has been found to be decreased in diabetic patients with complications or other risk factors for coronary artery disease $[7,8,9,11,12,13]$. However, studies with young type 1 diabetic subjects without complications have mainly shown normal coronary vasoreactivity $[10,12,13,14]$. The present study is the first study to examine the effect of hsCRP on coronary vasoreactivity in subjects with type 1 diabetes. To eliminate potential confounding factors and to specifically investigate the association between hsCRP and coronary vasoreactivity, the young type 1 diabetic subjects of this study had no diabetic complications or other diseases such as hypertension or dyslipidaemia. Consistent with the results of previous studies, we found that coronary vasoreactivity was normal when all patients with uncomplicated type 1 diabetes were pooled into one group. However, when diabetic subjects were divided into two groups based on hsCRP concentration, diabetic subjects with slightly elevated hsCRP had impaired coronary vasoreactivity, whereas in diabetic subjects with low hsCRP, coronary vasoreactivity was normal.

Increased hsCRP is associated with early-stage carotid atherosclerosis in young subjects with type 1 diabetes [24]. In the present study, coronary vasoreactivity was inversely correlated with hsCRP in diabetic subjects. The impaired coronary vasoreactivity found in diabetic subjects with slightly elevated hsCRP might indicate that these subjects are at increased risk of future cardiovascular events [2] and therefore would especially benefit from intensive treatment of cardiovascular risk factors. In peripheral vasculature, normalisation of elevated hsCRP concentrations is associated with a normalisation of endothelium-mediated flow in patients with coronary artery disease [25]. Therefore, further studies in patients with type 1 diabetes are needed to investigate the predictive value of impaired coronary vasoreactivity and the potential benefits of anti-inflammatory medications in this context.

Long-term diabetic complications are associated with increased hsCRP concentration [6], which could explain the elevated hsCRP concentrations in diabetic subjects in many previous studies. In one study in- 
volving patients with uncomplicated type 1 diabetes, who were at a similar age to the diabetic subjects of the present study, the average hsCRP concentration was $1.42 \mathrm{mg} / \mathrm{l}$ [26]. In that study, duration of diabetes was longer (approximately 20 years) than in the present study and smokers were included. The relatively low hsCRP concentrations in the present study support the finding that the diabetic subjects were actually otherwise healthy.

In the present study, synergistic effect of adenosine and insulin was used to measure the coronary vasoreactivity. Insulin induces and enhances vasodilation mainly by the endothelium-dependent mechanism [27]. A significant part of the adenosine-induced vasodilation is endothelium dependent [28], and therefore adenosineinduced vasodilation is an integrating measure of endothelial function and vascular smooth muscle relaxation. In contrast to under resting conditions where flow and myocardial work (oxygen consumption) are tightly coupled, metabolic control of myocardial blood flow is lost during adenosine stimulation, but endothelial and neurogenic controls are still functional [29].

Limitations. In the present study, inflammatory response factors other than hsCRP were not investigated. In addition, only a relatively small number of patients were studied. Despite the limited size of the study population we were able to demonstrate a significant association between elevated hsCRP and impaired coronary vasoreactivity in type 1 diabetic subjects. This finding, when considered together with epidemiological data on hsCRP and coronary events, suggests that hsCRP might have a pathophysiological effect on myocardial blood supply in subjects with type 1 diabetes. However, more studies addressing the effect of hsCRP on myocardial perfusion are needed to clarify its specific role in the development of coronary artery disease in diabetic subjects.

Conclusions. The present study demonstrates that even slightly elevated hsCRP concentrations are associated with impaired coronary vasoreactivity in young subjects with uncomplicated type 1 diabetes.

Acknowledgements. This study was financially supported by the grants of EVO from the Turku University Hospital (Finland), the Finnish Foundation for Cardiovascular Research (Helsinki, Finland), the Novo Nordisk Foundation (Gentofte, Denmark) and the Research Foundation of Orion (Espoo, Finland). We thank the staff of the Turku PET Centre for their excellent technical assistance.

\section{References}

1. Ridker PM, Cushman M, Stampfer MJ, Tracy RP, Hennekens CH (1997) Inflammation, aspirin, and the risk of cardiovascular disease in apparently healthy men. N Engl J Med 336:973-979
2. Vita JA, Treasure CB, Nabel EG et al. (1990) Coronary vasomotor response to acetylcholine relates to risk factors for coronary artery disease. Circulation 81:491-497

3. Bhagat K, Vallance P (1997) Inflammatory cytokines impair endothelium-dependent dilatation in human veins in vivo. Circulation 96:3042-3047

4. Makimattila S, Virkamaki A, Groop PH et al. (1996) Chronic hyperglycemia impairs endothelial function and insulin sensitivity via different mechanisms in insulin-dependent diabetes mellitus. Circulation 94:1276-1282

5. Zhang YX, Cliff WJ, Schoefl GI, Higgins G (1999) Coronary C-reactive protein distribution: its relation to development of atherosclerosis. Atherosclerosis 145:375-379

6. Saraheimo M, Teppo AM, Forsblom C, Fagerudd J, Groop PH (2003) Diabetic nephropathy is associated with lowgrade inflammation in Type 1 diabetic patients. Diabetologia 46:1402-1407

7. Nitenberg A, Valensi P, Sachs R, Dali M, Aptecar E, Attali JR (1993) Impairment of coronary vascular reserve and ACh-induced coronary vasodilation in diabetic patients with angiographically normal coronary arteries and normal left ventricular systolic function. Diabetes 42:1017-1025

8. Pitkanen OP, Nuutila P, Raitakari OT et al. (1998) Coronary flow reserve is reduced in young men with IDDM. Diabetes 47:248-254

9. Di Carli MF, Bianco-Batlles D, Landa ME et al. (1999) Effects of autonomic neuropathy on coronary blood flow in patients with diabetes mellitus. Circulation 100:813-819

10. Sundell J, Laine H, Nuutila P et al. (2002) The effects of insulin and short-term hyperglycemia on myocardial blood flow in young men with uncomplicated Type I diabetes. Diabetologia 45:775-782

11. Di Carli MF, Janisse J, Grunberger G, Ager J (2003) Role of chronic hyperglycemia in the pathogenesis of coronary microvascular dysfunction in diabetes. J Am Coll Cardiol 41:1387-1393

12. Stevens MJ, Dayanikli F, Raffel DM et al. (1998) Scintigraphic assessment of regionalized defects in myocardial sympathetic innervation and blood flow regulation in diabetic patients with autonomic neuropathy. J Am Coll Cardiol 31:1575-1584

13. Sundell J, Janatuinen T, Ronnemaa T et al. (2004) Diabetic background retinopathy is associated with impaired coronary vasoreactivity in people with Type 1 diabetes. Diabetologia 47:725-731

14. Laine H, Sundell J, Nuutila P et al. (2004) Insulin induced increase in coronary flow reserve is abolished by dexamethasone in young men with uncomplicated type 1 diabetes. Heart 90:270-276

15. Schalkwijk CG, Poland DC, van Dijk W et al. (1999) Plasma concentration of C-reactive protein is increased in type I diabetic patients without clinical macroangiopathy and correlates with markers of endothelial dysfunction: evidence for chronic inflammation. Diabetologia 42:351-357

16. DeFronzo RA, Tobin JD, Andres R (1979) Glucose clamp technique: a method for quantifying insulin secretion and resistance. Am J Physiol 237:E214-E223

17. Clark JC, Crouzel C, Meyer GJ, Strijckmans K (1987) Current methodology for oxygen-15 production for clinical use. Int J Rad Appl Instrum [A] 38:597-600

18. Crouzel C, Clark J, Brihaye C et al. (1993) Radiochemistry automation for PET. In: Stöckling G, Pike V (eds) Radiopharmaceuticals for positron emission tomography. Kluwer, Dordrecht

19. Laine H, Raitakari OT, Niinikoski H et al. (1998) Early impairment of coronary flow reserve in young men with borderline hypertension. J Am Coll Cardiol 32:147-153 
20. Iida H, Takahashi A, Tamura Y, Ono Y, Lammertsma AA (1995) Myocardial blood flow: comparison of oxygen-15water bolus injection, slow infusion and oxygen-15-carbon dioxide slow inhalation. J Nucl Med 36:78-85

21. Iida H, Rhodes CG, de Silva R et al. (1992) Use of the left ventricular time-activity curve as a noninvasive input function in dynamic oxygen-15-water positron emission tomography. J Nucl Med 33:1669-1677

22. Scheid DC, McCarthy LH, Lawler FH, Hamm RM, Reilly KE (2001) Screening for microalbuminuria to prevent nephropathy in patients with diabetes: a systematic review of the evidence. J Fam Pract 50:661-668

23. Feigenbaum H (1994) Echocardiography, 5th edn. Lippincott Williams \& Wilkins, London

24. Hayaishi-Okano R, Yamasaki Y, Katakami N et al. (2002) Elevated C-reactive protein associates with early-stage carotid atherosclerosis in young subjects with type 1 diabetes. Diabetes Care 25:1432-1438
25. Fichtlscherer S, Rosenberger G, Walter DH, Breuer S, Dimmeler S, Zeiher AM (2000) Elevated C-reactive protein levels and impaired endothelial vasoreactivity in patients with coronary artery disease. Circulation 102:10001006

26. Hansen TK, Thiel S, Knudsen ST et al. (2003) Elevated levels of mannan-binding lectin in patients with type 1 diabetes. J Clin Endocrinol Metab 88:4857-4861

27. Sobrevia L, Nadal A, Yudilevich DL, Mann GE (1996) Activation of L-arginine transport (system y+) and nitric oxide synthase by elevated glucose and insulin in human endothelial cells. J Physiol 490:775-781

28. Buus NH, Bottcher M, Hermansen F, Sander M, Nielsen TT, Mulvany MJ (2001) Influence of nitric oxide synthase and adrenergic inhibition on adenosine-induced myocardial hyperemia. Circulation 104:2305-2310

29. Opie LH (1998) The heart, 3rd edn. Lippincott-Raven, Philadelphia New York 